\title{
Effect of cyclosporin A intervention on the immunological mechanisms of coronary heart disease and restenosis
}

\author{
XUAN WANG ${ }^{1,2^{*}}$, YUE-CHENG HU ${ }^{2 *}$, RU-YAN ZHANG ${ }^{2}$, DONG-XIA JIN ${ }^{2}$, \\ YUAN JIANG $^{1}$, HE-NAN ZHANG ${ }^{2}$ and HONG-LIANG CONG ${ }^{2}$ \\ ${ }^{1}$ Cardiology Department, Tianjin Medical University, Tianjin 300070; \\ ${ }^{2}$ Cardiology Department, Tianjin Chest Hospital, Tianjin 300222, P.R. China
}

Received October 9, 2015; Accepted July 15, 2016

DOI: $10.3892 / \mathrm{etm} .2016 .3775$

\begin{abstract}
The present study aimed to investigate the effect of cyclosporin A (CSA) intervention on the immunological mechanisms underlying coronary heart disease (CHD) and restenosis $(\mathrm{RS})$ in rabbits. A total of 48 rabbits were randomly divided into normal control $(\mathrm{N}), \mathrm{N}+\mathrm{CSA}, \mathrm{CHD}$ model, CHD + CSA, RS model and RS + CSA groups. Rabbits in the respective groups received different treatments prior to sacrifice at the end of week 12. Iliac arteries were harvested from the rabbits for morphological analysis and to determine the mRNA and protein expression levels of cluster of differentiation (CD) 40/CD40 ligand (CD40L), CD134/CD134 ligand (CD134L) and inflammatory factors, including matrix metalloproteinase (MMP)-1, MMP-9, vascular cell adhesion protein (VCAM)-1, interleukin (IL)-6 and tumor necrosis factor (TNF)- $\alpha$, by reverse transcription-quantitative polymerase chain reaction and immunohistochemical staining. As compared with the $\mathrm{N}$ group, the mRNA expression levels of MMP-9, VCAM-1 and TNF- $\alpha$ were significantly increased in the CHD and RS groups $(\mathrm{P}<0.05)$, but were significantly decreased in the groups with CSA intervention, as compared with those without CSA intervention $(\mathrm{P}<0.05)$. Conversely, there were no significant differences in the expression levels of MMP-1 and IL-6 among the six groups, although a decreasing trend of IL-6 expression was observed following intervention with CSA. Furthermore, there were significant differences in the mRNA and protein expression levels of CD40/CD40L and CD134/CD134L among the N, CHD and RS groups $(\mathrm{P}<0.05)$, and between the groups with and without CSA intervention.
\end{abstract}

Correspondence to: Dr Hong-Liang Cong, Cardiology Department, Tianjin Chest Hospital, 261 Taierzhuang South Road, Jinnan, Tianjin 300222, P.R. China

E-mail: tjconghongliang@163.com

"Contributed equally

Key words: atherosclerosis, restenosis, coronary heart diseases, cluster of differentiation 40, cluster of differentiation 40 ligand, inflammatory factors, cyclosporin A
The present study demonstrated that CSA intervention exerted beneficial effects on CHD and RS, and further studies are required to investigate the mechanisms underlying the effects of CSA on CHD.

\section{Introduction}

Coronary heart disease (CHD) is the most common cause of mortality in Euramerican countries (1). Coronary vessels in patients with CHD undergo damage and stenosis, the abnormal narrowing of blood vessels, due to atherosclerosis (AS) (2). Coronary restenosis, additional vessel narrowing, may occur following percutaneous coronary intervention, the primary treatment for CHD, which may lead to severe complications. Dysregulation of immune responses has been shown to be an important initiating factor for the inflammatory reactions that characterize AS (3). Clinical and animal studies have suggested that the humoral and cellular immune responses of patients with CHD are in a hyperfunctional state, which may have an important role in the formation and development of atheromatous plaques in coronary arteries $(3,4)$. Cellular immunity is mediated by $\mathrm{T}$ cells and involves the synergistic effects of numerous inflammatory cells and inflammatory factors. The abnormal activation of $\mathrm{T}$ cells has been shown to have a role during each stage in the occurrence and development of AS $(5,6)$.

Costimulatory molecules, including cluster of differentiation (CD)40 and CD134, bind to their ligands (CD40L and CD134L) to mediate interactions between $\mathrm{T}$ lymphocytes and dendritic cells. These molecules have an important role in the innate and adaptive immune responses, and have been implicated in the pathogenesis of AS (7). Costimulatory molecules may also activate atheroma-associated cells to produce intercellular adhesion molecules (ICAM), cytokines, matrix metalloproteinases (MMP) and tissue factors that are involved in AS $(8,9)$.

Cyclosporin A (CSA), which is a type of immunosuppressant that exerts its effects predominantly via the inhibition of $\mathrm{T}$ cell activation processes, is widely used during organ transplantation and to treat autoimmune diseases $(10,11)$. Therefore, the present study aimed to investigate the roles of the costimulatory molecules CD40 and CD134, and inflammatory factors, in the formation and development of CHD and RS in a rabbit 
model, and to determine whether CSA intervention was able to attenuate the development of AS.

\section{Materials and methods}

Animals. A total of 48 healthy male New Zealand White rabbits (age, 3-5 months; weight, 2.3-3.0 kg) were randomly divided into six groups (8 rabbits/group), as follows: Normal control (N) group; $\mathrm{N}+\mathrm{CSA}$ group; CHD model group; CHD + CSA group; RS model group; and RS + CSA group. The present study was approved by the ethics committee of Tianjin Chest Hospital. The $\mathrm{N}$ and $\mathrm{N}+\mathrm{CSA}$ groups received a normal diet of vegetables and grains. The CHD and CHD + CSA groups received a $1.5 \%$ cholesterol diet and underwent iliac artery balloon injury at the end of week 4 . The RS and RS + CSA groups also received a $1.5 \%$ cholesterol diet, but underwent iliac artery balloon injury at the ends of weeks 4 and 8 . In addition, the $\mathrm{N}+\mathrm{CSA}, \mathrm{CHD}+\mathrm{CSA}$ and RS + CSA groups were administered $10 \mathrm{mg} / \mathrm{kg} /$ day CSA (Novartis International AG, Basel, Switzerland) for 4 weeks by gavage. Rabbits were maintained in individual cages at temperatures of $19-25^{\circ} \mathrm{C}$ and $42-68 \%$ humidity, under a natural day/night cycle. Rabbits had unlimited access to water, and were sacrificed at the end of week 12 for harvesting of the iliac arteries. This was performed by inhalation of anesthesia; rabbits were administered $10 \mathrm{mg} / \mathrm{ml}$ ketamine hydrochloride at a volume of $1 \mathrm{ml} / \mathrm{kg}$ of body weight (Jiuan Wuhan Pharmaceutical Co., Ltd., Wuhan, China)

Reverse transcription-quantitative polymerase chain reaction (RT-qPCR). Sections of the iliac arteries were used to measure the mRNA expression levels of CD40/CD40L, CD134/CD134L and the inflammatory factors MMP-1, MMP-9, vascular cell adhesion protein (VCAM)-1, interleukin (IL)-6 and tumor necrosis factor (TNF)- $\alpha$ by RT-qPCR. Briefly, total RNA was extracted from the iliac arteries and homogenized in liquid nitrogen, following which $1 \mathrm{ml}$ TRIzol (Promega Corporation, Madison, WI, USA) was added. The purity and quantity of total RNA was determined using an ultraviolet spectrophotometer, and was used at a concentration of 1.08-1.752 $\mu \mathrm{g} / \mu \mathrm{l}$. Reverse transcription was conducted in a two-step reaction, as follows: i) $0.4 \mu \mathrm{l}$ random primers, $7.6 \mu \mathrm{l}$ double-distilled $\mathrm{H}_{2} \mathrm{O}$ and $2.0 \mu \mathrm{l}$ RNA, incubated at $70^{\circ} \mathrm{C}$ for $5 \mathrm{~min}$; and ii) $2.5 \mu \mathrm{l}$ double-distilled $\mathrm{H}_{2} \mathrm{O}, 2.0 \mu \mathrm{l} 10 \mu \mathrm{M}$ deoxynucleotide solution, $4.0 \mu 15 \mathrm{X}$ buffer, $0.5 \mu \mathrm{l}$ RNase, $1.0 \mu$ l Moloney Murine Leukemia Virus Reverse Transcriptase (all Promega Corporation) at $37^{\circ} \mathrm{C}$ for $60 \mathrm{~min}$, followed by incubating the reaction mix at $95^{\circ} \mathrm{C}$ for $5 \mathrm{~min}$. qPCR was performed on the Applied Biosystems 7500 Real-Time PCR System (Thermo Fisher Scientific, Inc., Waltham, MA, USA) using $10.0 \mu \mathrm{l}$ SYBR Green PCR Premix (Takara Bio, Inc., Otsu, Japan) with a reaction system consisting of $0.4 \mu \mathrm{l}$ ROX Reference Dye II, $0.5 \mu \mathrm{l}$ each of the forward and reverse primers, $1.0 \mu \mathrm{l}$ cDNA (diluted 10 times), and $7.6 \mu 1$ double-distilled $\mathrm{H}_{2} \mathrm{O}$. PCR cycling conditions were $95^{\circ} \mathrm{C}$ for $30 \mathrm{sec}$, followed by 45 cycles of $95^{\circ} \mathrm{C}$ for $5 \mathrm{sec}$ and $62^{\circ} \mathrm{C}$ for $34 \mathrm{sec}$. Primer sequences were as follows: CD40 forward, 5'-AATGCGTAGACGGCACCA AC-3' and reverse, 5'-CAGGCATCGCTGATGCAATG-3'; CD40L forward, 5'-A ACGAGAAGGGTCCTTATCC-3' and reverse, 5'-CCAAAGTGTTGCTCATGGTG-3'; CD134 forward, 5'-CGAGGCTGTCAACTACCAAG-3' and reverse, 5'-GTCCGCTTCCCAGCTAAGG-3'; CD134L forward, 5'-TTCTGTGCCTCACCTACGTC-3' and reverse, 5'-CAC ACTGCAGGATGACGACTGAG-3'; and glyceraldehyde 3-phosphate dehydrogenase (GAPDH) forward, 5'-GTGATG CTGGTGCCGAGTAC-3' and reverse, 5'-GGTGGCAGTGAT GGCGTGC-3'. These were provided by Beijing Liuhe Huada Gene Technology Company, Beijing, China. RT-qPCR was performed in 3 repeats. Relative mRNA expression levels normalized to GAPDH were determined using the $2^{-\Delta \Delta C q}$ method (12).

Histological analysis. Another part of the iliac arteries was used for histological analyses. Briefly, the rabbit iliac arteries were embedded in paraffin and cut into 5- $\mu \mathrm{m}$ sections. The sections were dried at $45^{\circ} \mathrm{C}$ for $\sim 4 \mathrm{~h}$. Following dewaxing with dimethylbenzene, the sections were treated with 3,3'-diaminobenzidine and hematoxylin and eosin. Subsequently, the sections were mounted using neutral gum and observed under a light microscope.

Immunostaining. For immunostaining, the sections were incubated with rabbit anti-CD40 monoclonal antibody (cat. no. ab58391; 1:400; Abcam, Cambridge, UK), rabbit anti-CD40L monoclonal antibody (cat. no. ab52750; 1:400; Abcam), rabbit anti-CD134 polyclonal antibody (cat. no. ab76000; 1:400; Abcam) and rabbit anti-CD134L polyclonal antibody (cat. no. ab76130; 1:400; Abcam) for $1 \mathrm{~h}$ at $37^{\circ} \mathrm{C}$. These were then incubated with MaxVision HRP-Polymer anti-mouse/rabbit IHC Kit (Fuzhou Maixin Biotechnology Co. Ltd., Fuzhou, Fujian) for $20 \mathrm{~min}$ at $37^{\circ} \mathrm{C}$ and visualized using IHC Antibody Diluent (Fuzhou Maixin Biotechnology Co. Ltd.). The sections were observed under a microscope, and the levels of expression were analyzed using a HMIAS-2000 analysis system. The positive rate was defined as the percentage of cells with yellow or brown membranes or plasma in a high-power field. For every section, images were captured of three high-power fields to obtain a mean positive rate.

Statistical analysis. SPSS 18.0 software (SPSS, Inc., Chicago, IL, USA) was used for statistical analyses. Continuous variables are presented as the mean \pm standard deviation. One-way analysis of variance was performed to compare differences among groups, while Fisher's least significant difference test was used to compare two groups. Categorical variables are expressed as percentages or frequencies. To compare count data, the $\chi^{2}$ test was applied, although Fisher's exact probability method was used when any form of the theory frequency was $<5$. Furthermore, a linear correlation analysis was performed. $\mathrm{P}<0.05$ was considered to indicate a statistically significant difference.

\section{Results}

Morphology of iliac arteries. In the $\mathrm{N}$ and $\mathrm{N}+\mathrm{CSA}$ groups, the lumens of the iliac arteries were regular, the thickness of the vessel wall was uniform, the vessel walls were thin and the inner and outer elastic plates were clear and complete. In addition, the endothelial cell nuclei were stained blue and 
$\mathbf{A}$

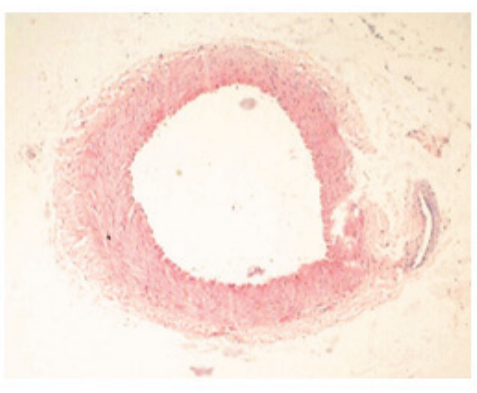

C

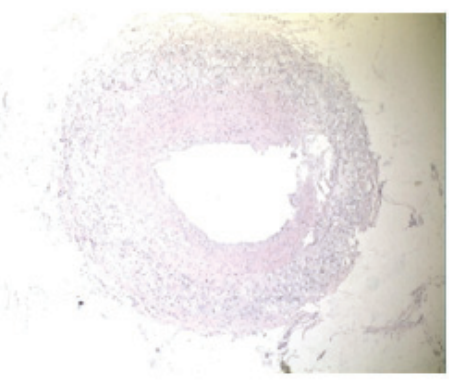

$\mathbf{E}$

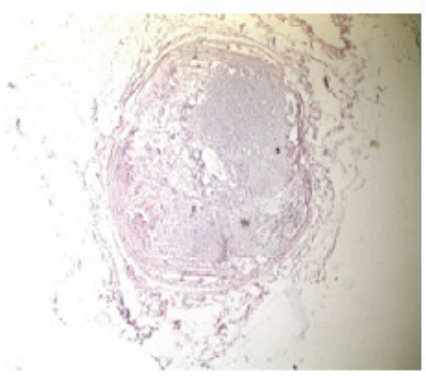

B

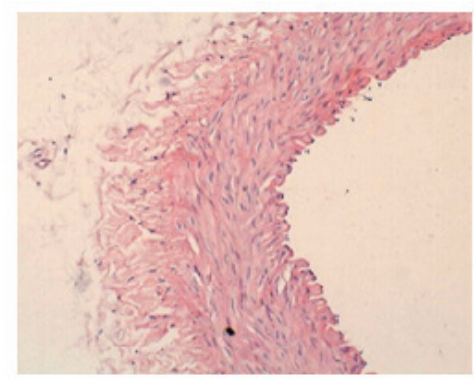

D

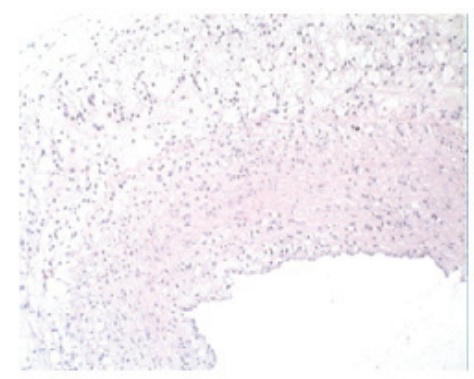

$\mathbf{F}$

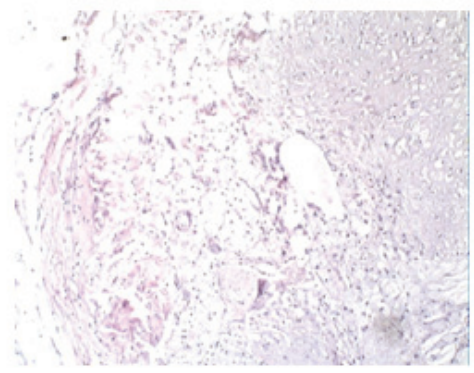

Figure 1. Histological analysis of rabbit iliac arteries. (A) Cross-section of the iliac artery from the normal control (N) + cyclosporin A (CSA) group [hematoxylin and eosin (HE) staining; magnification, x40]. (B) Cross-section of the iliac artery from the $\mathrm{N}$ group (HE staining; magnification, $\mathrm{x} 100$ ). (C) Cross-section of the iliac artery from the coronary heart disease (CHD) + CSA group (HE staining; magnification, $x 40)$. (D) Cross-section of the iliac artery from the CHD group (HE staining; magnification, x100). (E) Cross-section of the iliac artery from the restenosis (RS) + CSA group (HE staining; magnification, x40). (F) Cross-section of the iliac artery from the RS group (HE staining; magnification, x100).

were aligned, and the intima was shown to be predominantly composed of monolayer endothelial cells and inner elastic plate. In the $\mathrm{N}$ group, smooth muscle cells (SMCs) were aligned, the nuclei were fusiform and SMCs had not migrated to the endothelium (Fig. 1A and B).

The blood vessel walls of the CHD group were thicker compared with the $\mathrm{N}$ group, and the lumen was narrower with eccentric stenosis. Furthermore, the intima of the vessel wall was significantly hyperplastic, the inner elastic plate had a discontinuous fracture and SMCs were arranged randomly. A large number of SMCs had migrated to the endothelium and hyperplasia after breaking through the inner elastic, and had formed foam cells and fibrous connective tissue in the CHD group. The pathological appearance of the CHD + CSA group was similar to the CHD group (Fig. 1C and D).

In the RS and RS + CSA groups, the vascular lumen showed severe stenosis, with some of the lumens appearing almost entirely occluded. In addition, the intimal hyperplasia was more severe compared with the CHD group, and the hyperplastic cells were disordered in their arrangement. A large number of SMCs, phagocytes and foam cells were observed, and fibrous connective tissue and small blood vessel regeneration was apparent. The damage to the inner elastic plate was severe, while there was no clear boundary between the endangium and tunica media in the RS group (Fig. 1E and F).

mRNA expression levels of inflammatory factors. mRNA expression levels of MMP-1 were decreased in the experimental groups, as compared with the $\mathrm{N}$ group, although the difference was not significant $(\mathrm{P}>0.05)$. The mRNA expression levels of IL-6 were significantly increased in the CHD group, as compared with the $\mathrm{N}$ group $(\mathrm{P}<0.05)$; a decrease in mRNA expression levels of IL-6 in CHD + CSA and RS + CSA groups compared with the CHD and RS groups, respectively, but this was not statistically significantly different $(\mathrm{P}>0.05)$. The mRNA expression levels of MMP-9, VCAM-1, and TNF- $\alpha$ were markedly elevated in the CHD and RS groups, as compared with the $\mathrm{N}$ group, and the mRNA expression levels of TNF- $\alpha$ were significantly increased in the RS group, as compared with the $\mathrm{N}$ and $\mathrm{N}+\mathrm{CSA}$ groups $(\mathrm{P}<0.05)$. Furthermore, there were significant differences in the mRNA expression levels of MMP-9, VCAM-1 and TNF- $\alpha$ between the CHD and CHD + CSA groups, and the RS and $\mathrm{RS}+\mathrm{CSA}$ groups $(\mathrm{P}<0.05)$. However, as compared with the CHD group, there was no significant difference in the mRNA expression levels of any of these inflammatory factors in the RS group (Table I). 
Table I. Relative mRNA expression levels of MMP-1, MMP-9, VCAM-1, IL-6 and TNF- $\alpha$ in rabbit ilial arteries (n=8/group).

\begin{tabular}{|c|c|c|c|c|c|}
\hline Group & MMP-1 & MMP-9 & VCAM-1 & IL-6 & TNF- $\alpha$ \\
\hline $\mathrm{N}$ & $1.04 \pm 0.41$ & $1.00 \pm 0.03$ & $1.03 \pm 0.33$ & $1.01 \pm 0.17$ & $1.03 \pm 0.24$ \\
\hline $\mathrm{N}+\mathrm{CSA}$ & $0.74 \pm 0.07$ & $1.08 \pm 0.12$ & $1.37 \pm 0.43$ & $1.01 \pm 0.10$ & $1.06 \pm 0.48$ \\
\hline CHD & $0.69 \pm 0.18$ & $2.25 \pm 0.62^{\mathrm{a}}$ & $3.20 \pm 2.59^{\mathrm{b}}$ & $1.09 \pm 0.33^{\mathrm{b}}$ & $2.24 \pm 0.62^{\mathrm{a}}$ \\
\hline $\mathrm{CHD}+\mathrm{CSA}$ & $0.64 \pm 0.19$ & $1.81 \pm 0.51^{\mathrm{c}}$ & $0.99 \pm 1.05^{\mathrm{c}}$ & $0.95 \pm 0.30$ & $2.08 \pm 0.97^{\mathrm{c}}$ \\
\hline $\mathrm{RS}$ & $0.60 \pm 0.21^{\mathrm{a}, \mathrm{b}}$ & $1.60 \pm 0.81^{\mathrm{b}}$ & $3.03 \pm 1.19^{\mathrm{b}}$ & $0.88 \pm 0.37$ & $3.34 \pm 1.72^{\mathrm{a}, \mathrm{c}}$ \\
\hline $\mathrm{RS}+\mathrm{CSA}$ & $0.77 \pm 0.26$ & $0.75 \pm 0.46^{\mathrm{d}}$ & $2.81 \pm 0.86^{\mathrm{d}}$ & $0.85 \pm 0.06$ & $2.24 \pm 2.10^{\mathrm{d}}$ \\
\hline
\end{tabular}

Data are presented as the mean \pm standard deviation. ${ }^{a} \mathrm{P}<0.01,{ }^{b} \mathrm{P}<0.05$ vs. the $\mathrm{N}$ group. ${ }^{\mathrm{c}} \mathrm{P}<0.05$ vs. the CHD group, ${ }^{\mathrm{d}} \mathrm{P}<0.05$ vs. the $\mathrm{RS}$ group. $\mathrm{N}$, normal control; CHD, coronary heart disease; RS, restenosis; CSA, cyclosporin A; MMP, matrix metalloproteinase; VCAM-1, vascular cell adhesion protein-1; TNF- $\alpha$, tumor necrosis factor- $\alpha$; IL-6, interleukin-6.

Table II. Relative mRNA expression levels of CD40/CD40L and CD134/CD134L in the rabbit iliac arteries (n=8/group).

\begin{tabular}{lcccc}
\hline Group & CD40 & CD40L & CD134 & CD134L \\
\hline $\mathrm{N}$ & $0.99 \pm 0.28$ & $1.01 \pm 0.15$ & $1.03 \pm 0.00$ & $1.05 \pm 0.00$ \\
$\mathrm{~N}+\mathrm{CSA}$ & $1.00 \pm 0.20$ & $1.03 \pm 0.32$ & $1.18 \pm 0.23$ & $1.03 \pm 0.39$ \\
$\mathrm{CHD}$ & $1.05 \pm 0.34$ & $1.48 \pm 0.01$ & $1.45 \pm 1.16$ & $2.04 \pm 0.21$ \\
$\mathrm{CHD}+\mathrm{CSA}$ & $1.03 \pm 0.29$ & $1.28 \pm 0.00^{\mathrm{a}}$ & $1.21 \pm 0.76^{\mathrm{b}}$ & $1.91 \pm 0.10^{\mathrm{a}}$ \\
$\mathrm{RS}$ & $1.53 \pm 0.13$ & $2.39 \pm 0.34$ & $3.22 \pm 0.38$ & $3.85 \pm 0.35$ \\
$\mathrm{RS}+\mathrm{CSA}$ & $1.29 \pm 0.70^{\mathrm{c}}$ & $1.87 \pm 0.17^{\mathrm{c}}$ & $2.82 \pm 0.47^{\mathrm{c}}$ & $2.77 \pm 0.29^{\mathrm{c}}$ \\
P-value & 0.052 & 0.031 & 0.024 & 0.012 \\
\hline
\end{tabular}

P-value indicates comparisons among the N, CHD and RS groups. Data are presented as the mean \pm standard deviation. ${ }^{\mathrm{a}} \mathrm{P}<0.05$ and ${ }^{\mathrm{b}} \mathrm{P}<0.01$ vs. the CHD group; ${ }^{\mathrm{C}} \mathrm{P}<0.05$ vs. the RS group. CD40, cluster of differentiation 40; CD40L, CD40 ligand; CD134, cluster of differentiation 134; CD134L, CD134 ligand; N, normal control; CHD, coronary heart disease; RS, restenosis; CSA, cyclosporin A.

Table III. Correlation of the mRNA expression levels of CD40/CD40L and CD134/CD134L

\begin{tabular}{lll}
\hline Group & CD134 & CD134L \\
\hline CD40 & $0.970^{\mathrm{a}}$ & $0.961^{\mathrm{a}}$ \\
CD40L & $0.962^{\mathrm{a}}$ & $0.992^{\mathrm{a}}$ \\
\hline
\end{tabular}

${ }^{a} \mathrm{P}<0.01$. CD40, cluster of differentiation 40; CD40L, CD40 ligand; CD134, cluster of differentiation 134; CD134L, CD134 ligand.

mRNA expression levels of CD40/CD40L and CD134/CD134L. As is shown in Fig. 2, the mRNA expression levels of CD40/CD40L and CD134/CD134L exhibited an increasing trend in the N, CHD and RS groups, with a significant difference among the groups $(\mathrm{P}<0.05$; Table II). Notably, the relative mRNA expression levels of CD40/CD40L and CD134/CD134L were significantly decreased in the CHD + CSA group, as compared with the CHD group $(\mathrm{P}<0.05)$, and the same was observed for the RS + CSA group, as compared with the RS group $(\mathrm{P}<0.05$; Table II). Linear correlation analysis showed that the mRNA expression levels of CD40/CD40L were positively correlated with those of CD134/CD134L $(\mathrm{P}<0.01)$. Specific correlation coefficients are shown in Table III.

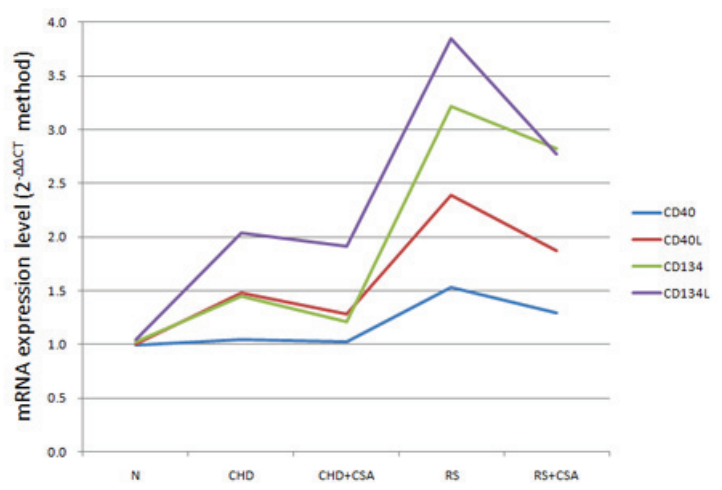

Figure 2. mRNA expression levels of CD40/CD40L and CD134/CD134L in each group. $\mathrm{N}$, normal control; $\mathrm{CHD}$, coronary heart disease; RS, restenosis; CSA, cyclosporin A; CD40, cluster of differentiation 40; CD40L, CD40 ligand; CD134, cluster of differentiation 134; CD134L, CD134 ligand.

Protein expression levels of CD40/CD40LandCD134/CD134L. The rates of CD40/CD40L- and CD134/CD134L-positive cells in the vessel walls were significantly increased in the CHD and RS groups compared with the $\mathrm{N}$ group $(\mathrm{P}<0.05)$. In addition, there were significant differences in the rates of CD40/CD40L- and CD134/CD134L-positive cells between the CHD + CSA and CHD groups, and the RS + CHD and RS groups $(\mathrm{P}<0.05$; Table IV). 
Table IV. Rates of CD40/CD40L and CD134/CD134L positive cells in rabbit ilial arteries (n=8/group).

\begin{tabular}{lcccc}
\hline Group & CD40 (\%) & CD40L $(\%)$ & CD134 (\%) & CD134L $(\%)$ \\
\hline $\mathrm{N}$ & $10.42 \pm 8.32$ & $4.09 \pm 5.37$ & $3.01 \pm 2.05$ & $6.97 \pm 3.11$ \\
$\mathrm{~N}+$ CSA & $11.23 \pm 6.37$ & $9.01 \pm 6.79$ & $2.57 \pm 1.97$ & $5.52 \pm 2.35$ \\
CHD & $63.34 \pm 8.52^{\mathrm{a}}$ & $50.53 \pm 17.98^{\mathrm{a}}$ & $26.05 \pm 12.32^{\mathrm{a}}$ & $41.73 \pm 11.77^{\mathrm{a}}$ \\
CHD + CSA & $58.37 \pm 9.81^{\mathrm{b}}$ & $45.09 \pm 11.37^{\mathrm{b}}$ & $25.91 \pm 10.33^{\mathrm{b}}$ & $37.03 \pm 14.82^{\mathrm{b}}$ \\
RS & $64.86 \pm 9.34^{\mathrm{a}}$ & $53.00 \pm 18.53^{\mathrm{a}}$ & $27.74 \pm 10.73^{\mathrm{a}}$ & $43.06 \pm 17.61^{\mathrm{a}}$ \\
RS + CSA & $62.32 \pm 8.35^{\mathrm{c}}$ & $49.31 \pm 17.35^{\mathrm{c}}$ & $24.41 \pm 14.38^{\mathrm{c}}$ & $39.15 \pm 16.84^{\mathrm{c}}$ \\
\hline
\end{tabular}

Data are presented as the mean \pm standard deviation. ${ }^{\mathrm{a}} \mathrm{P}<0.01$ vs. the $\mathrm{N}$ group, ${ }^{\mathrm{b}} \mathrm{P}<0.05$ vs. the $\mathrm{CHD}$ group, ${ }^{\mathrm{C}} \mathrm{P}<0.05$ vs. the $\mathrm{RS}$ group. $\mathrm{CD} 40$, cluster of differentiation 40; CD40L, CD40 ligand; CD134, cluster of differentiation 134; CD134L, CD134 ligand; N, normal control; CHD, coronary heart disease; RS, restenosis; CSA, cyclosporin A.

Table V. Correlations between the mRNA expression levels of CD40/CD40L and CD134/CD134L and neointimal proliferation and vascular remodeling.

\begin{tabular}{lcccccc}
\hline Marker & IT & IA & IA/MA & IHI & LA & IEL \\
\hline CD40 & $0.894^{\mathrm{a}}$ & $0.953^{\mathrm{a}}$ & 0.851 & 0.778 & -0.536 & $0.939^{\mathrm{a}}$ \\
CD40L & $0.953^{\mathrm{a}}$ & $0.936^{\mathrm{a}}$ & $0.911^{\mathrm{a}}$ & $0.880^{\mathrm{a}}$ & -0.685 & $0.945^{\mathrm{a}}$ \\
CD134 & $0.939^{\mathrm{a}}$ & $0.995^{\mathrm{b}}$ & $0.883^{\mathrm{a}}$ & 0.833 & -0.599 & $0.923^{\mathrm{a}}$ \\
CD134L & $0.959^{\mathrm{b}}$ & $0.916^{\mathrm{a}}$ & $0.941^{\mathrm{a}}$ & $0.904^{\mathrm{a}}$ & -0.737 & $0.929^{\mathrm{a}}$ \\
\hline
\end{tabular}

${ }^{\mathrm{a}} \mathrm{P}<0.05,{ }^{\mathrm{b}} \mathrm{P}<0.01$. IT, intimal thickness; IA, intimal area; MA, media area; IHI, intima hyperplasia index; LA, lumen area; IEL, internal elastic lamin; EEL, external elastic lamina; CD40L, CD40 ligand; CD134, cluster of differentiation 134; CD134L, CD134 ligand.

Table VI. Correlations between the rates of CD40/CD40L and CD134/CD134L positive cells and neointimal proliferation and vascular remodeling.

\begin{tabular}{|c|c|c|c|c|c|c|c|}
\hline Marker & IT & IA & IM & IHI & LA & IEL & EEL \\
\hline CD40 & $0.911^{\mathrm{a}}$ & 0.721 & $0.897^{\mathrm{a}}$ & $0.972^{\mathrm{b}}$ & $-0.955^{\mathrm{a}}$ & 0.725 & 0.727 \\
\hline CD40L & 0.811 & 0.546 & 0.845 & $0.925^{\mathrm{a}}$ & $-0.994^{b}$ & 0.545 & 0.555 \\
\hline CD134 & 0.785 & 0.512 & 0.842 & $0.903^{\mathrm{a}}$ & $-0.985^{b}$ & 0.507 & 0.522 \\
\hline CD134L & 0.819 & 0.556 & 0.859 & $0.928^{a}$ & $-0.990^{b}$ & 0.552 & 0.564 \\
\hline
\end{tabular}

${ }^{\mathrm{a}} \mathrm{P}<0.05,{ }^{\mathrm{b}} \mathrm{P}<0.01$. IT, intimal thickness; IA, intimal area; MA, media area; IHI, intima hyperplasia index; LA, lumen area; IEL, internal elastic lamin; EEL, external elastic lamina; CD40L, CD40 ligand; CD134, cluster of differentiation 134; CD134L, CD134 ligand.

Correlation analysis. Correlation analysis demonstrated that the mRNA expression levels of CD40/CD40L and CD134/CD134L were positively correlated with the intimal thickness, intimal area, internal elastic lamin and external elastic lamina of the rabbit iliac arteries $(\mathrm{P}<0.05$; Table $\mathrm{V})$. In addition, the rates of CD40/CD40L- and CD134/CD134Lpositive cells were positively correlated with the intima hyperplasia index $(\mathrm{P}<0.05)$, but negatively correlated with the lumen area $(\mathrm{P}<0.05$; Table $\mathrm{VI})$.

\section{Discussion}

CSA is a type of immune inhibitor with a high efficiency and low toxicity that is widely used in the treatment of various autoimmune diseases, aplastic anemia and other hematological diseases (13). To date, few studies have investigated the inhibitory effect of CSA on the local inflammatory responses and factors associated with the formation of AS $(14,15)$. Therefore, the present study aimed to evaluate the effect of CSA intervention on the expression levels of local inflammatory factors in the iliac arteries of rabbit models of CHD and RS, in order to determine whether CSA exerts a protective effect against AS.

In a previous study, MMPs expressed by macrophages were shown to degrade extracellular matrix, thin the fibrous cap of plaque and promote plaque rapture (16). The expression of MMPs is regulated by numerous cytokines, although it is predominantly regulated via the induction of CD40/CD40L signaling $(17,18)$. MMP-9 is more prevalent and has a higher activity in plaque than other subtypes of MMPs (19). Consistent with this, the present study did not demonstrate a significant 
difference in MMP-1 expression among the groups, except between the RS and $\mathrm{N}$ groups. Conversely, the expression of MMP-9 showed an increasing trend in the RS and CHD groups, as compared with the normal feeding group, thus suggesting that MMP-9 expression is upregulated during the process of AS. Notably, the expression levels of MMP-9 were significantly reduced following CSA intervention in both the CHD + CSA and RS + CSA groups .

CSA has been shown to inhibit inflammatory processes by mediating $\mathrm{T}$ lymphocyte inactivation and inhibiting various signaling pathways in the cytokine network. In the experimental groups, the expression levels of VCAM-1 and TNF- $\alpha$ were significantly decreased by CSA intervention. Cyclophilin A (CyPA) is a receptor of CSA that also participates in cellular cholesterol transport $(20,21)$. Under the action of oxidized-low-density lipoprotein (LDL), CyPA activation may occur, which promotes cholesterol and LDL accumulation and leads to the surface expression of VCAM-1 on endothelial cells, thereby exacerbating inflammation (15). In addition, in a previous study, CyPA induced endothelial cell dysfunction and apoptosis via TNF (4). Therefore, the binding of CSA to CyPA may inhibit AS. Previous studies of organ transplantation in rats have suggested that CSA is able to downregulate the expression of TNF- $\alpha$ (22-24). In the present study, the relative expression levels of IL-6 were slightly reduced in the CSA intervention groups as compared with the groups that did not receive the intervention, although the difference was not significant. Conversely, a previous study reported that CSA did not reduce the serum levels of IL- 6 in a rabbit model of CHD (25). The differences in these findings may be due to the animal species, animal specificity of the antibody and the total sample size used.

Costimulatory molecules, CD40/CD40L and CD134/CD134L, have an important role in the signal transduction pathway of inflammation (26). The interaction of CD40 with its ligand can induce $\mathrm{T}$ lymphocytes to produce cytokines, including IL-1, IL-6 and TNF- $\alpha$, and to upregulate the expression of adhesion and costimulatory molecules (VCAM-1, ICAM-1, CD80 and CD86), resulting in the induction of monocytes, SMCs and endothelial cells $(9,27)$. A combination of these inflammatory factors and CD40/CD40L interaction initiates immune responses, leading to the proliferation of endothelial cells, migration of SMCs, release of cytokines from fat cells, and the subsequent acceleration of the formation and progression of AS (27). Zirlik et al (28) demonstrated that CD40L interacts with the integrin Mac-1 on the surface of macrophages to promote the adhesion and migration of inflammatory cells. However, there is a limited number of previous studies that have investigated the association between CD134/CD134L and CHD. CD134/CD134L was shown to regulate the differentiation of $\mathrm{T}$ lymphocytes to promote $\mathrm{T}$ cell responses (29), and to induce the proliferation and differentiation of B lymphocytes to secrete immunoglobulin (30). It was suggested that the CD134L gene was an AS susceptibility gene in rats, and various genotypes of CD134L were associated with the incidence of human myocardial infarction (31). Together, these findings suggested that the interaction of CD40/CD40L and CD134/CD134L axes underlie the pathophysiological process of CHD and RS in animal models, which is consistent with the results of the present study.
CSA has been shown to inhibit protein kinase $\mathrm{C}$ and calcineurin, and block the expression of the CD40L gene and functioning of CD40-dependent T lymphocytes (32). Furthermore, a previous study demonstrated that CSA downregulated the expression of CD40L by inhibiting transcription factors of the nuclear factor of activated $\mathrm{T}$ cell family, which are substrates of calcineurin and are required for the expression of CD40L (32). Research has shown that the mitochondrial permeability transition pore (mPTP), which is closed during myocardial ischemia and open during reperfusion, may cause reperfusion injury in the open state (33). Therefore, as an mPTP blocker, CSA may attenuate reperfusion injury and improve the prognosis of patients with CHD (34). In addition, the results of the present study suggested that CSA may influence the occurrence and development of CHD via inhibition of the CD40/CD40L and CD134/CD134L axes.

The present study had some limitations. The protocol used only observed the expression of five inflammatory cytokines of local tissue and alterations in their expression levels following CSA intervention; thus, the study failed to further clarify the role of other inflammatory factors in the pathogenesis of AS and RS, and the intervention effect of CSA. Although CSA may attenuate AS by inhibiting immune responses, the underlying mechanisms remain unclear.

In conclusion, the present study demonstrated that CSA significantly decreases expression of inflammatory factors (MMP-9, VCAM-1 and TNF- $\alpha$ ) and costimulatory molecules (CD40, CD40L, CD134 and CD134L) in humoral and cellular immune responses, which are closely associated with the occurrence of AS and CHD. It suggested that CSA intervention exerted beneficial effects on CHD and RS. These findings provide a basis for future studies, which will provide novel ideas and strategies for the prevention and treatment of CHD and RS.

\section{Acknowledgements}

The present study was supported by the Natural Science Foundation of China (grant no. 51171058), the Tianjin Science and Technology Major Program (grant no. 12ZCZDSY03200), the Tianjin Municipal Health Bureau Key Program in Science and Technology (grant no. 10KG122), and the Tianjin Municipal Health Bureau Science and Technology Foundation (grant no. 2011KZ64)

\section{References}

1. Grundy SM, Benjamin IJ, Burke GL, Chait A, Eckel RH, Howard BV, Mitch W, Smith SC Jr and Sowers JR: Diabetes and cardiovascular disease: A statement for healthcare professionals from the American heart association. Circulation 100: 1134-1146, 1999.

2. DeFeudis FV: Coronary atherosclerosis: Current therapeutic approaches and future trends. Life Sci 49: 689-705, 1991.

3. Hansson GK and Libby P: The immune response in atherosclerosis: A double-edged sword. Nat Rev Immunol 6: 508-519, 2006.

4. Lamb DJ, Eales LJ and Ferns GA: Immunization with bacillus Calmette-Guerin vaccine increases aortic atherosclerosis in the cholesterol-fed rabbit. Atherosclerosis 143: 105-113, 1999.

5. Salonen JT, Ylä-Herttuala S, Yamamoto R, Butler S, Korpela H, Salonen R, Nyyssönen K, Palinski W and Witztum JL: Autoantibody against oxidised LDL and progression of carotid atherosclerosis. Lancet 339: 883-887, 1992. 
6. Hansson GK: Immune mechanisms in atherosclerosis. Arterioscler Thromb Vasc Biol 21: 1876-1890, 2001.

7. Lievens D, Zernecke A, Seijkens T, Soehnlein O, Beckers L, Munnix IC, Wijnands E, Goossens P, van Kruchten R, Thevissen L, Boon L et al: Platelet CD40L mediates thrombotic and inflammatory processes in atherosclerosis. Blood 116 4317-4327, 2010.

8. Schönbeck U, Mach F, Sukhova GK, Atkinson E, Levesque E, Herman M, Graber P, Basset P and Libby P: Expression of stromelysin-3 in atheorsclerotic lesions: Regulation via CD40-CD40Ligand signaling in vitro and in vivo. J Exp Med 189: 843-853, 1999.

9. Schönbeck U, Mach F, Sukhova GK, Herman M, Graber P, Kehry MR and Libby P: CD40Ligation induces tissue factor expression in human vascular smooth muscle cells. Am J Pathol 156: 7-14, 2000.

10. Lallemand F, Felt-Baeyens O, Besseghir K, Behar-Cohen F and Gurny R: Cyclosporine A delivery to the eye: A pharmaceutical challenge. Eur J Pharm Biopharm 56: 307-318, 2003.

11. Noble S and Markham A: Cyclosporin: A review of the pharmacokinetic properties, clinical efficacy and tolerability of a microemulsion-based formulation. Drugs 50: 924-941, 1995.

12. Livak KJ and Schmittgen TD: Analysis of relative gene expression data using real-time quantitative PCR and the 2(-Delta Delta C(T)) Method. Methods 25: 402-408, 2001.

13. Muehlschlegel JD: Closing the pore on reperfusion injury: Myocardial protection with cyclosporine. Anesthesiology 121 212-213, 2014.

14. Sazliyana S, Mohd Shahrir MS, Kong CT, Tan HJ, Hamidon BB, and Azmi MT: Implications of immunosuppressive agents in cardiovascular risks and carotid intima media thickness among lupus nephritis patients. Lupus 20: 1260-1266. 2011.

15. Nigro P, Satoh K, O'Dell MR, Soe NN, Cui Z, Mohan A, Abe J, Alexis JD, Sparks JD and Berk BC: Cyclophilin A is an inflammatory mediator that promotes atherosclerosis in apolipoprotein E-deficient mice. J Exp Med 208: 53-66, 2011.

16. Poston RN, Haskard DO, Coucher JR, Gall NP and Johnson-Tidey RR: Expression of intercellular adhesion molecule-1 in atherosclerotic Plaques. Am J Pathol 140: 665-673, 1992.

17. Zeitler H, Ko Y, Zimmermann C, Nickenig G, Glänzer K, Walger P, Sachinidis A and Vetter H: Elevated serum concentrations of soluble adhesion molecules in coronary artery disease and acute myocardial infarction. Eur J Med Res 2: 389-394, 1997.

18. Bou Khzam L, Boulahya R, Abou-Saleh H, Hachem A, Zaid Y and Merhi Y: Soluble CD40 ligand stimulates the pro-angiogenic function of peripheral blood angiogenic outgrowth cells via increased release of matrix metalloproteinase-9. PLoS One 8: e84289, 2013.

19. LI H, Cybulsdy MI, Gimbrone MA Jr and Libby P: Inducible expression of vascular cell adhesion molecule-1 by vascula smooth muscle cells in vitro and within rabbit atheroma. Am J Pathol 143: 1551-1559, 1993.

20. Smart EJ, Ying Y, Donzell WC and Anderson RG: A role for caveolin in transport of cholesterol from endoplasmic reticulum to plasma membrane. J Biol Chem 271: 29427-29435, 1996.
21. Hu J, Zhang Z, Shen WJ and Azhar S: Cellular cholesterol delivery, intracellular processing and utilization for biosynthesis of steroid hormones. Nutr Metab (Lond) 7: 47, 2010.

22. Hamada H, Suzuki H, Abe J, Suzuki Y, Suenaga T, Takeuchi T, Yoshikawa N, Shibuta S, Miyawaki M, Oishi K, Yamaga H et al: Inflammatory profiles during Cyclosporin treatment for immunoglobulin-resistant Kawasaki disease. Cytokine 60: 681-685, 2012.

23. Joo YH, Chang DY, Kim JH, Jung MH, Lee J, Cho HJ, Jeon SY, Kim SJ and Kim SW: Anti-inflammatory effects of intranasal cyclosporine for allergic rhinitis in a mouse model. Int Forum Allergy Rhinol 2016.

24. Massuda TY, Nagashima LA, Leonello PC, Kaminami MS, Mantovani MS, Sano A, Uno J, Venancio EJ, Camargo ZP, and Itano EN: Cyclosporin A treatment and decreased fungal load/antigenemia in experimental murine paracoccidioidomycosis. Mycopathologia 171:161-169, 2011.

25. Houssen ME, Haron MM, Metwally SS and Ibrahim TM: Effects of immunomodulatory drugs on plasma inflammatory markers in a rabbit model of atherosclerosis. J Physiol Biochem 67: 115-120, 2011.

26. Watts TH: TNF/TNFR family members in costimulation of T cell responses. Annu Rev Immunol 23: 23-68, 2005.

27. Antoniades C, Bakogiannis C, Tousoulis D, Antonopoulos AS and Stefanadis C: The CD40/CD40 ligand system: Linking inflammation with atherothrombosis. J Am Coll Cardiol 54: 669-677, 2009.

28. Zirlik A, Maier C, Gerdes N, MacFarlane L, Soosairajah J, Bavendiek U, Ahrens I, Ernst S, Bassler N, Missiou A, et al: CD40Ligand mediates inflammation independently of CD40 by interaction with Mac-1. Circulation 115: 1571-1580, 2007.

29. Hauer AD, Uyttenhove C, de Vos P, Stroobant V, Renauld JC, van Berkel TJ, van Snick J and Kuiper J: Blockade of interleukin-12 function by protein vaccination attenuates atherosclerosis. Circulation 112: 1054-1062, 2005.

30. Lee TS, Yen HC, Pan CC and Chau LY: The role of interleukin 12 in the development of atherosclerosis in ApoE-deficient mice. Arterioscler Thromb Vasc Biol 19: 734-742, 1999.

31. Wang X, Ria M, Kelmenson PM, Eriksson P, Higgins DC, Samnegård A, Petros C, Rollins J, Bennet AM, Wiman B, et al: Positional identification of TNFSF4, encoding OX40 ligand, as a gene that influences atherosclerosis susceptibility. Nat Genet 37: 365-372, 2005

32. Gupta AK, Giaglis S, Hasler P and Hahn S: Efficient neutrophil extracellular trap induction requires mobilization of both intracellular and extracellular calcium pools and is modulated by cyclosporine A. PLoS One 9: e97088, 2014.

33. Mewton N, Croisille P, Gahide G, Rioufol G, Bonnefoy E, Sanchez I, Cung TT, Sportouch C, Angoulvant D, Finet G, et al: Effect of cyclosporine on left ventricular remodeling after reperfused myocardial infarction. J Am Coll Cardiol 55: 1200-1205, 2010.

34. Dabrowski MJ: Is further improvement of the treatment of acute coronary syndromes still possible. Postepy Kardiol Interwencyjnej 9: 41-44, 2013. 